\title{
Examination of an attempt to improve rapeseed cultivation in France in order to reduce the greenhouse gas emissions of biodiesel ${ }^{\text {th }}$
}

\author{
Francis Flénet*, Dominique Wagner and Pascal Simonin \\ Terres Inovia, Avenue Lucien Brétignières, 78850 Thiverval-Grignon, France
}

Received 1 February 2020 - Accepted 13 November 2020

\begin{abstract}
Démarche de progrès DIESTER" was an attempt by French farmers, industrialists, technicians, agricultural cooperatives and private grain trading companies to continuously improve the environmental performance of rapeseed biodiesel. The objective was to implement certain rapeseed cultivation operations that had shown their efficiency in previous studies to reduce greenhouse gas (GHG) emissions: (i) the use of decision support systems (DSS) to calculate nitrogen fertilisation rates, (ii) the cultivation of legumes as intercrops with rapeseed or (iii) as previous crops. This paper first presents an estimate of the potential GHG effects of these cultivation operations, using results from previous studies obtained under experimental conditions or using crop modelling. It then presents the level of adoption by

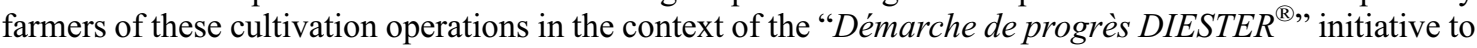
continuously improve the environmental performance of rapeseed biodiesel. Depending on the year, 39 to 74 agricultural cooperatives and grain trading companies were involved in the study, and 90170 to 283480 hectares of rapeseed have been monitored. This is the first time in France that an attempt to improve cultivation operations for environmental reasons has been made on such a scale. The average GHG reduction values, compared to fossil fuels, varied from 49.5 to $55.8 \%$ depending on the year, which was most often above the $50 \%$ minimum reduction value for sustainable biodiesel, but well below the $70 \%$ minimum for very low GHG emission biodiesel. Using the results of previous studies, this article shows that the widespread use of decision support systems to calculate mineral $\mathrm{N}$ fertilizer rates, and the cultivation of legumes as a preceding crop or intercrop, would make it possible to significantly reduce GHGs and make it possible to produce very low GHG-emitting biodiesel in certain locations and/or years. However, the actual changes in cultural operations were too small to be effective. The reasons for this lack of impact and how to achieve results in the future are discussed in this article.
\end{abstract}

Keywords: greenhouse gas / oilseed rape / cultivation operations / continuous improvement

Résumé - Étude d'une tentative d'amélioration des pratiques culturales du colza en France, dans le but de réduire les émissions de gaz à effet de serre du biodiesel. La " démarche de progrès DIESTER " était une tentative d'amélioration en continu des bilans environnementaux du biodiesel de colza qui a mobilisé les agriculteurs français, les industriels, les organismes agricoles de conseil et de R\&D, ainsi que les organismes stockeurs. L'objectif était de mettre en œuvre certaines pratiques culturales qui avaient montré dans de précédentes études leur efficacité pour réduire les émissions de gaz à effet de serre (GES) : (i) l'utilisation d'un outil d'aide à la décision pour calculer la dose d'engrais azoté, (ii) la culture de légumineuses en association avec le colza ou (iii) en précédent cultural. Cet article présente tout d'abord une estimation des effets potentiels sur les GES de ces pratiques culturales, en utilisant les résultats de précédentes études obtenus en expérimentation ou par modélisation. Il présente ensuite le niveau d'adoption de ces pratiques par les agriculteurs dans le cadre de la démarche de progrès DIESTER ${ }^{\circledR}$. Suivant les années, de 39 à 74 organismes stockeurs ont participé à la démarche et 90170 à 283480 ha de colza ont été suivis. C'est la première fois qu'une démarche de progrès pour améliorer les bilans environnementaux a été

\footnotetext{
H) Contribution to the Topical Issue "Biodiesel / Biodiesel".

*Correspondence: $f$.flenet@terresinovia.fr
} 
entreprise à une telle échelle en France. Suivant les années, le gain de GES permis par le biodiesel a été de 49,5 à $55,8 \%$ par rapport aux émissions du gazole fossile. L'objectif de $50 \%$ pour que le biodiesel soit considéré comme durable a ainsi été atteint la plupart du temps, mais le gain a toujours été bien inférieur à la valeur de $70 \%$ demandée pour le biodiesel à très bas niveau de GES. En utilisant les résultats de précédentes études, cet article montre que la généralisation de l'utilisation d'un outil d'aide à la décision pour calculer la dose d'engrais azoté minéral et la culture de légumineuses, comme précédent cultural ou en association avec le colza, permettraient de réduire significativement les GES et rendraient possible la production de biodiesel à très bas niveau de GES dans certains territoires ou dans certaines années. Mais, l'évolution des pratiques culturales réellement observée a été trop limitée pour avoir un effet significatif sur les GES. La raison de ce manque de résultats et la manière dont il faudrait s'y prendre pour réussir sont discutés dans cet article.

Mots clés : gaz à effet de serre / colza / pratiques culturales / démarche de progrès

\section{Introduction}

The European Directive on the promotion of the use of energy from renewable sources (Directive 2009/28/EC) aims both at reducing greenhouse gas (GHG) emissions, in order to contribute to compliance with the Kyoto Protocol to the United Nations Framework Convention on Climate Change, and at reducing the transport sector's dependence on oil imports. This European directive also stipulates that the production of biofuels must meet sustainability criteria. One of these criteria is a reduction of GHG emissions from the use of biofuels and bioliquids by at least 50\% from 1 January 2017 (60\% from 1 January 2018 for biofuels and bioliquids produced in installations where production started on or after 1 January 2017). GHG emissions are calculated by adding emissions from the extraction or cultivation of raw materials, carbon stock changes due to land-use change, processing, transport and distribution, fuel used and emission savings (carbon accumulation in soils through improved agricultural management, carbon capture and geological storage, etc.). The Directive provided a default value for $\mathrm{GHG}$ emissions from rapeseed raw material of $29 \mathrm{~g} \mathrm{CO}_{2}$ equivalent $\mathrm{MJ}^{-1}$. GHG emissions from the cultivation of agricultural raw materials were also calculated in areas classified at level 2 of the nomenclature of territorial units (NUTS2), which is the regional level in France. In this country, all rapeseed NUTS2 values were less than or equal to $29 \mathrm{~g}$ of $\mathrm{CO}_{2}$ equivalent $\mathrm{MJ}^{-1}$, except in Provence-Alpes-Côte d'Azur. With such values, the $50 \%$ GHG reduction is achieved if the carbon stock changes caused by indirect land-use change are not taken into account, but there are demands to account for indirect land-use changes due to biofuel production. In addition, in recent years, several countries such as Germany or Sweden have set a mandatory target for biofuel use expressed as the amount of $\mathrm{CO}_{2}$ saved, instead of the amount of biofuel, which has led to an increase in the price of very low GHG-emitting biofuels ( $70 \%$ savings and more). For these reasons, it appeared necessary to reduce GHG emissions from rapeseed cultivation in France.

Since 2007, French farmers, industrialists, technicians, agricultural cooperatives and private grain trading companies have joined forces to continuously improve the environmental performance of rapeseed biodiesel at all stages of its value chain. This initiative, called "Démarche de progrès DIES$T E R^{\circledR}$ ", was led by Terres Inovia, Avril Group and Saipol. Starting in 2010, it was decided to calculate the GHG emissions of rapeseed each year for cooperatives and grain trading companies that supply rapeseed to Saipol. In 2010, the variability of GHG emissions was high, ranging from 30-32 to 42-44 $\mathrm{g} \mathrm{CO}_{2}$ equivalent $\mathrm{MJ}^{-1}$ for emissions including transportation and biodiesel processing (Flénet, 2012). This variability is mainly due to differences in nitrogen applications and seed yields. Compared to fossil fuel emissions $\left(83.8 \mathrm{~g} \mathrm{CO}_{2}\right.$ eq. $\left.\mathrm{MJ}^{-1}\right)$, in 2010 , almost all values were $50 \%$ lower or less. However, Flénet (2012) showed that this $50 \%$ GHG reduction criterion could not be met by half of the cooperatives or grain trading companies in years of poor seed yield performance. The potential to reduce GHGs by improving the efficiency of mineral $\mathrm{N}$ fertilization was demonstrated, while the application of organic matter appeared to be largely ineffective due to increased soil $\mathrm{N}_{2} \mathrm{O}$ emissions. Thus, from 2013/2014 to $2016 / 2017$, the biodiesel producer SAIPOL decided to promote improved cultivation operations by farmers, to reduce GHG emissions from rapeseed, by providing financial support to cooperatives and grain trading companies that would engage in actions to improve nitrogen use efficiency or seed yield. This article focuses on the three actions to improve nitrogen use efficiency that have been proposed to cooperatives or grain trading companies. These actions have proven to be effective in previous studies. The first action was the use of Decision Support Systems (DSS) to calculate nitrogen fertilization rates. In a previous study, using a survey on the use of DSS in France and crop modelling, Ben Aoun (2015) showed that in 2011/12 in France, the generalization of DSS and their good use would have led to both a $27 \mathrm{~kg} \mathrm{~N}^{-1}$ decrease in mineral nitrogen fertilization and an only slight decrease in yield. These results were validated by experimental data. The second and third actions were the cultivation of leguminous crops, intercropped with rapeseed or as a previous crop. Experimental data obtained for different years and locations showed that it would decrease the optimal $\mathrm{N}$ fertilization rate by 30 (Cadoux et al., 2015) and 40 to 50 (Dumans et al., 2010) $\mathrm{kg} \mathrm{N} \mathrm{ha}^{-1}$ respectively. Christen and Sieling (1995) reported an increase in the yield of rapeseed grown after a pea crop compared to a cereal preceding crop. In the work of Dumans et al. (2010), who studied a range of mineral $\mathrm{N}$ fertilization, the effect of a previous pea crop on seed yield depended on the level of $\mathrm{N}$ fertilization: an effect was only observed for sub-optimal $\mathrm{N}$ fertilization.

A large participation of French farmers, and their cooperatives or grain trading companies, was obtained by SAIPOL. This is the first time that an attempt to improve cultivation operations in order to reduce the environmental impacts of agriculture, and involving the entire value chain, has been made on such a scale. 
Table 1. Greenhouse gas (GHG) emissions of oilseed rape and of biodiesel, seed yields and nitrogen applications from 2012/2013 to 2016/2017 ( \pm confidence intervals at $5 \%$ ).

\begin{tabular}{|c|c|c|c|c|c|}
\hline & $2012 / 2013$ & $2013 / 2014$ & $2014 / 2015$ & $2015 / 2016$ & $2016 / 2017$ \\
\hline Oilseed rape area* (ha) & 209720 & 283480 & 242360 & 96570 & 90170 \\
\hline GHG of biodiesel $\left(\mathrm{g} \mathrm{CO}_{2} \mathrm{MJ}^{-1}\right)$ & $42.3 \pm 1.3$ & $37.3 \pm 0.7$ & $38.1 \pm 0.8$ & $41.6 \pm 1.1$ & $37.0 \pm 0.8$ \\
\hline Seed yield $\left(\mathrm{tha}^{-1}\right)$ & $3.39 \pm 0.11$ & $3.87 \pm 0.9$ & $3.76 \pm 0.10$ & $3.42 \pm 0.09$ & $4.03 \pm 0.14$ \\
\hline Mineral nitrogen application $\left(\mathrm{kg} \mathrm{N} \mathrm{ha}^{-1}\right)$ & $161.8 \pm 7.5$ & $155.9 \pm 6.9$ & $157.1 \pm 7.7$ & $165.3 \pm 7.1$ & $163.1 \pm 6.5$ \\
\hline
\end{tabular}

${ }^{*}$ The area was calculated by assuming an average area of 10 ha per field.

The first objective of this paper was to assess the potential GHG effect of improved cultivation operations that have been proposed to cooperatives or grain trading companies, using published results on their effects on $\mathrm{N}$ use efficiency. The second objective was to report and discuss the level of adoption of these improvements in order to highlight the conditions for successful change in cultivation operations.

\section{Materials and methods}

Cultivation operations and seed yields were collected from cooperatives or private grain trading companies from 2012/13 to $2016 / 17$ to calculate GHG emissions. The number of agricultural cooperatives or grain trading companies involved ranged from 39 to 74 , depending on the year, while the number of rapeseed fields surveyed ranged from 9017 to 28348 (Tab. 1). Information from existing databases was used as much as possible, but in some cooperatives/trading companies it was necessary to survey farmers. The total area of rapeseed was estimated by assuming that the average field size was 10 hectares, which is a rough estimate of the average area of arable fields in France. In 2015/16 and 2016/17, additional information was collected in order to assess the implementation of actions to improve cultivation operations: the previous crop, intercropping with legumes sensitive to frost and the use of a DSS to calculate the mineral fertilizer $\mathrm{N}$ rate. In France, the DSSs are based on a simplified nitrogen balance method (Makowski et al., 2005) which calculates the amount of fertilizer based on crop requirements (expected yield multiplied by the amount of nitrogen to be absorbed per unit of yield + nitrogen remaining in the soil after harvest) and estimated soil nitrogen input (nitrogen already absorbed by plants + mineral nitrogen in the soil at the end of winter + mineralization of soil humus + nitrogen input from organic fertilization). The amount of nitrogen already taken up by rapeseed is estimated from the measurement of fresh plant matter or from remote sensing. A rough estimate of plant biomass can also be obtained from visual observations. The objectives of cooperatives/trading companies to improve cultivation operations were also recorded.

Cultivation operations recorded were tillage (tillage tools used and number of tillage operations), application of organic matter (amount and type) and application of mineral $\mathrm{N}$ fertilizer (amount and type). The amount of organic $\mathrm{N}$ applied was calculated from the amount of organic matter and the average percentage of $\mathrm{N}$ in each type of organic matter. Soil type was also recorded. Tillage fuel consumption and resulting GHG emissions, as well as GHG emissions from tillage implement production and engine oil use, were calculated from published data for each type of tillage implement and each soil type (Godron, 1992; ITCF, 1995). GHG emissions due to the application of organic matter, as well as those resulting from harvesting, were also calculated using data from Godron (1992) and ITCF (1995).

Applications of herbicides, insecticides, fungicides and growth regulators were not recorded, as GHG emissions from the production and application of these products are small relative to total emissions. Therefore, an average GHG value could be used with little effect on the accuracy of the total GHG emission values. This average value was calculated from a previous survey on the application of chemicals to winter rapeseed, and from data on GHG emissions for the production of these chemicals (Green, 1987; Gaillard et al., 1997). Fuel consumption, tool production and engine oil use for chemical applications were also considered.

Greenhouse gas emissions from nitrogen fertilization represented both fertilizer production and field application. Emissions from nitrogen fertilizer production are highly dependent on the technology and fossil fuel source used for this production. Thus, the values used in this study are typical values for French agriculture (Gac et al., 2009). Typical French values for the production of $\mathrm{P}_{2} \mathrm{O}_{5}$ and $\mathrm{K}_{2} \mathrm{O}$ fertilizers were also used, but the quantities of these fertilizers were estimated, instead of being studied, as the quantities applied are often different from the quantities needed for crops. For example, in soils with high levels of $\mathrm{P}_{2} \mathrm{O}_{5}$ and/or $\mathrm{K}_{2} \mathrm{O}$, farmers may not apply fertilizer. Farmers may also apply these fertilizers to rapeseed to fertilize both this crop and subsequent cereal crops. Therefore, the amounts of $\mathrm{P}_{2} \mathrm{O}_{5}$ and $\mathrm{K}_{2} \mathrm{O}$ used in the GHG calculations were estimated from production (i.e. seed yield multiplied by the percentages of $\mathrm{P}_{2} \mathrm{O}_{5}$ and $\mathrm{K}_{2} \mathrm{O}$ in the seed which are $1.34 \%$ and $1 \%$ respectively).

$\mathrm{N}_{2} \mathrm{O}$ emissions from soils were estimated using the Intergovernmental Panel on Climate Change Tier 1 methodology (De Klein et al., 2006). Emissions from biodiesel processing and transport were the average values for France published by BIO IS (2010), which are 7.1 and $1.47 \mathrm{~g} \mathrm{CO}_{2}$ eq. $\mathrm{MJ}^{-1}$, respectively. This GHG emission value for biodiesel processing is three times lower than the standard value of European 
Table 2. Effect of the generalization and the proper use of Decision Support Systems (DSS), of legume as a preceding crop or of intercropping frost-sensitive legumes on greenhouse gas emissions (GHG), seed yields of oilseed rape and nitrogen applications.

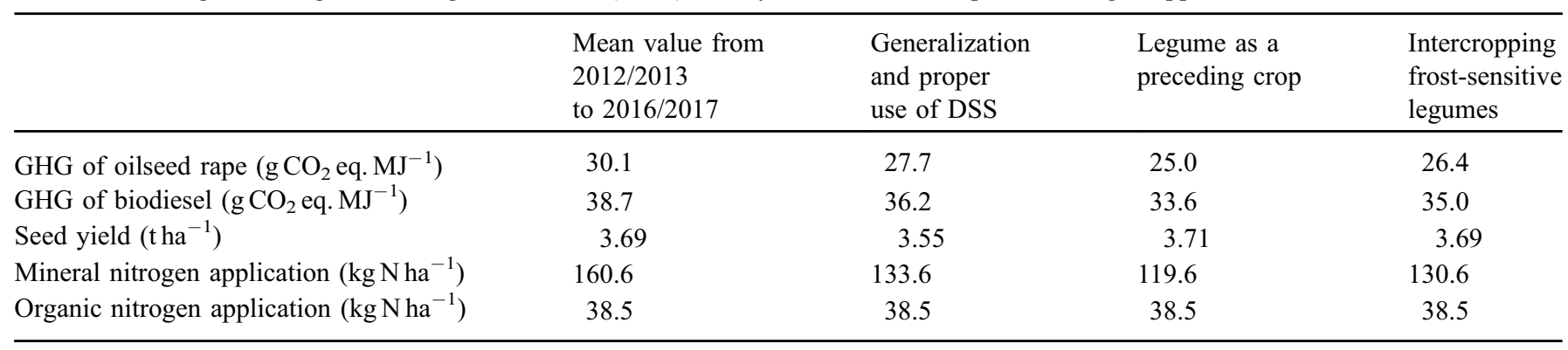

Directive 2009/28/EC, as French processing units are more efficient than most European units. In addition, the value of the European directive is $40 \%$ higher than the European average value, in order to force biofuel producers to use real values. No other emissions have been taken into account (i.e. carbon stock changes caused by iLUC, carbon accumulation in soils through better agricultural management, etc.).

GHG emissions have been split between the main product (biodiesel) and co-products according to their energy content, as recommended by European Directive 2009/28/EC. The GHG reduction value of rapeseed biodiesel (GHG_S) was calculated from the estimated emissions of this biofuel (GHG B) and the emissions of fossil diesel, which are $83.8 \mathrm{~g} \mathrm{CO}_{2}$ eq. $\mathrm{MJ}^{-1}$ (European Directive 2009/28/EC):

$$
\text { GHG_S }(\%)=100(83.8-\text { GHG_B }) / 83.8 \text {. }
$$

The $5 \%$ confidence intervals and KHI-2 tests to compare cultivation operations over several years were calculated using EXCEL software (Microsoft corp.).

\section{Results}

The results on seed yields, nitrogen applications and greenhouse gas (GHG) emissions are presented in Table 1. In the first 3 years, about 70 cooperatives or companies, which contracted with SAIPOL for the supply of rapeseed, participated in the survey to calculate GHGs. During this period, about 210000 to 280000 hectares of rapeseed were surveyed, which corresponded to about 15 to $20 \%$ of the total area of rapeseed cultivated in France. In addition to participating in the survey, most cooperatives or companies were also involved in efforts to improve farmers' cultivation operations. This first period of 3-year contracts was followed by a second period where fewer cooperatives or companies contracted for the supply of rapeseed seeds with SAIPOL. As a result, the number of participants and the area under study decreased. No significant effect of the improvement efforts was observed on the mineral nitrogen fertilizer rate. Therefore, the variability in GHGs from year to year was mainly due to differences in seed yield which were likely the result of climatic effects. For example, using the value published by BIO IS (2010) for rapeseed biodiesel processing $\left(7.1 \mathrm{~g} \mathrm{CO}_{2}\right.$ eq. $\left.\mathrm{MJ}^{-1}\right)$ and transportation and distribution $\left(1.47 \mathrm{~g} \mathrm{CO}_{2}\right.$ eq. $\left.\mathrm{MJ}^{-1}\right)$, GHG savings compared to fossil fuel $\left(83.8 \mathrm{gCO}_{2}\right.$ eq. $\left.\mathrm{MJ}^{-1}\right)$ ranged from 49.5 to $55.8 \%$. These GHG reduction values were well below the minimum $70 \%$ savings for the very low GHG-emitting biofuel.

Table 2 presents multi-year average values for seed yields, mineral and organic $\mathrm{N}$ fertilizer applications, which were calculated from the annual values presented in Table 1. Average GHG emissions were calculated from these average values. Table 2 also presents an estimate of the effects of improved cultivation operations on the amount of $\mathrm{N}$ fertilizers and on seed yields, based on previously published studies. These results show the potential effects of improved cultivation operations if they are adopted. The effects of generalization and proper use of Decision Support Systems (DSS) were derived from the study by Ben Aoun (2015): $27 \mathrm{~kg} \mathrm{Nha}^{-1}$ decrease in $\mathrm{N}$ mineral fertilization and $3.9 \%$ decrease in yields. These results were obtained from an extensive survey, carried out in 2012, on the use of DSS in France. For each fertilization practice identified in the survey, Ben Aoun (2015) ran the CERES-EGC agro-ecosystem model (Gabrielle et al., 2006) for 21 years to simulate crop yields. In his study, the simulated effect of nitrogen fertilization on seed yields was validated by the results of 65 experiments conducted in different locations in France from 2007/08 to 2011/12. Estimation of the effects of rapeseed cultivation after a legume preceding crop was based on the results of Dumans et al. (2010) and other unpublished results: 8 experiments conducted in different locations in France from 2007/08 to $2009 / 10$. On average, the results showed a $41 \mathrm{~kg} \mathrm{Nha}^{-1}$ decrease in the optimal $\mathrm{N}$ fertilizer rate and a $0.02 \mathrm{tha}^{-1}$ increase in optimal seed yield. The effect of intercropping legumes with rapeseed was studied in 14 experiments conducted at 2 to 4 sites in France from 2010/11 to 2013/14 (Cadoux et al., 2015). The average effects were a decrease of $30 \mathrm{~kg} \mathrm{~N}^{-1}$ in the optimal fertilizer rate with no effect on seed yield. All of these previously published results were used in this study to calculate the potential effects of improved cropping operations on GHGs (Tab. 2). Growing rapeseed after a legume preceding crop is the most effective way to reduce GHG emissions. The average value over the 5 years of the study would be $25.0 \mathrm{~g} \mathrm{CO}_{2}$ eq. $\mathrm{MJ}^{-1}$ for the rapeseed cultivation and $33.6 \mathrm{~g} \mathrm{CO}_{2}$ eq. $\mathrm{MJ}^{-1}$ for biodiesel, resulting in a $60 \%$ reduction in $\mathrm{GHG}$ emissions compared to fossil fuels. The effect of widespread and proper use of DSS would have been half less, and the effect of intercropping with frostsensitive legumes would have been intermediate. These results 
Table 3. Evolution of cultivation practices in cooperatives or companies commited to improvement efforts.

\begin{tabular}{|c|c|c|}
\hline & \multicolumn{2}{|c|}{$\%$ of the total area } \\
\hline & $2015 / 2016$ & $2016 / 2017$ \\
\hline \multicolumn{3}{|l|}{$\begin{array}{l}\text { Decision Support System to calculate the rate of } \mathrm{N} \text { fertilizer } \\
\text { by taking into account the biomass at the end of winter }\end{array}$} \\
\hline No tool is used & 10.5 & $16.4^{\mathrm{S}}$ \\
\hline Tool with visual estimation of the biomass & 28.6 & $30.4^{\mathrm{NS}}$ \\
\hline Tool with estimation of the biomass by weighing & 36.6 & $30.0^{\mathrm{S}}$ \\
\hline Tool with estimation of the biomass by remote sensing & 24.3 & $23.2^{\mathrm{NS}}$ \\
\hline $\begin{array}{l}\text { Difference between the amount of } \mathrm{N} \text { fertilizer actually applied } \\
\text { and the calculated rate within }-10 \text { to } 10 \mathrm{~kg} \mathrm{Nha}^{-1}\end{array}$ & 52.5 & $42.3^{\mathrm{S}}$ \\
\hline Rapeseed cultivated after a legume preceding crop & 2.0 & $2.9^{\mathrm{S}}$ \\
\hline Rapeseed cultivated with frost sensitive legumes & 1.1 & $1.9^{\mathrm{S}}$ \\
\hline
\end{tabular}

Note: S/NS: significant/not significant differences at $5 \%$.

Table 4. Evolution of the use of Decision Support Systems (DSS) to calculate the rate of $\mathrm{N}$ fertilizer among cooperatives or trading companies aiming at increasing this use.

\begin{tabular}{|c|c|c|c|}
\hline \multirow[t]{2}{*}{$\begin{array}{l}\text { Objective of the cooperatives or trading } \\
\text { companies }\end{array}$} & \multirow[t]{2}{*}{$\begin{array}{l}\text { Number of cooperatives } \\
\text { or companies }\end{array}$} & \multicolumn{2}{|c|}{$\begin{array}{l}\% \text { of oilseed rape area conducted with a DSS and with } \\
\text { an estimation of the biomass by weighing or remote sensing }\end{array}$} \\
\hline & & $2015 / 2016$ & $2016 / 2017$ \\
\hline $\begin{array}{l}\text { The objective is not quantified as a \% } \\
\text { of increase in the total area }\end{array}$ & 8 & 22.9 & $18.0^{\mathrm{NS}}$ \\
\hline
\end{tabular}

Note: S/NS: significant/not significant differences at $5 \%$.

are average values over several years and several sites. This suggests that the production of very low GHG-emitting rapeseed biodiesel is possible in France in some locations and/ or years if improvements are adopted. Furthermore, the combination of these improvements would further reduce GHGs and would be an effective way to produce very low GHG-emitting biodiesel more frequently.

Due to the lack of changes in mineral nitrogen fertilizer rates, additional questions were asked in the survey in 2015/2016 and 2016/2017 to assess the improvement efforts of cooperatives or trading companies. Table 3 presents the evolution of cultivation operations in the 30 cooperatives or trading companies engaged in improvement efforts during these 2 years. In the first year, almost $40 \%$ of the rapeseed area was cultivated without DSS or with a visual and approximate biomass estimation. In addition, when a DSS was used, the difference between the nitrogen fertilizer rate and the calculated value was more than $10 \mathrm{~kg} \mathrm{Nha}^{-1}$ on almost $50 \%$ of the cultivated area. In the following year, no improvement was observed and the situation was even worse in terms of the percentage of DSS use, the percentage of estimated biomass by weighing and the difference between the calculated and applied rates. On the contrary, there was a significant increase in rapeseed cultivation after a legume preceding crop or intercropped with frost-sensitive legumes, but the percentage of the rapeseed area concerned remained very low (less than 3\%).

Most of the 30 cooperatives or trading companies engaged in improvement efforts chose to increase the use of DSS with biomass estimation by weighing or remote sensing (Tab. 4). However, the target was not ambitious or was not quantified. It was never more than a $30 \%$ increase and even less than $10 \%$ for 7 cooperatives or trading companies among the 12 with a quantified objective. Moreover, no significant improvement was observed the following year, despite the targets that these cooperatives or trading companies set themselves. A significant decrease was even observed in the cooperatives or trading companies with the lowest improvement objectives. 
Table 5. Evolution of the agreement between the amount of $\mathrm{N}$ fertilizer actually applied and the calculated rate, among cooperatives or trading companies aiming at decreasing the differences between the two.

\begin{tabular}{llll}
\hline Objective & $\begin{array}{l}\text { Number of cooperatives } \\
\text { or companies }\end{array}$ & $\begin{array}{c}\text { \% of the total area with differences between N applied and } \\
\mathrm{N} \text { calculated ranging from }-10 \text { to }+10 \mathrm{~kg} \mathrm{~N} \mathrm{ha}\end{array}$ & $2016 / 2017$ \\
\hline $\begin{array}{l}\text { Amount of } \mathrm{N} \text { fertilizer } \\
=\text { calculated rate } \pm 10 \mathrm{~kg} \mathrm{Nha}^{-1}\end{array}$ & 1 & 55.4 & $20.3 \mathrm{~S}$ \\
$\begin{array}{l}\text { Amount of } \mathrm{N} \text { fertilizer } \\
=\text { calculated rate }+0 \text { to }+10 \%\end{array}$ & 1 & 55.3 & 56.7 NS \\
\hline
\end{tabular}

Note: S/NS: significant/not significant differences at $5 \%$.

Table 6. Evolution of the cultivation of legumes as preceding crops or as intercropped plants, among cooperatives or trading companies aiming at increasing this cultivation.

\begin{tabular}{llll}
\hline Objective & $\begin{array}{l}\text { Number of cooperatives } \\
\text { or companies }\end{array}$ & $\begin{array}{c}\text { \% of the total area of oilseed rape cultivated } \\
\text { after legumes or with intercropped legumes }\end{array}$ \\
\hline $\begin{array}{l}\text { Grain legumes as preceding crops } \\
+5 \% \text { in the total area of rapeseed }\end{array}$ & 1 & 4.2 & $2016 / 2017$ \\
$\begin{array}{l}\text { The objective is not quantified } \\
\begin{array}{l}\text { Oilseed rape intercropped with frost } \\
\text { sensitive legumes (the objective is not quantified) }\end{array}\end{array}$ & 1 & 0 & 0 \\
\hline
\end{tabular}

Similar results were obtained for cooperatives or trading companies aiming either at reducing the gap between calculated and applied nitrogen fertilizer rates (Tab. 5) or at increasing the area of rapeseed cultivated after a legume preceding crop (Tab. 6). For example, one cooperative decided to reduce the gap between the calculated and applied rate of nitrogen fertilizer, but the result was a 35\% decrease in area with less than $10 \mathrm{~kg} \mathrm{Nha}^{-1}$ between the two! The only improvement was the successful increase in the area of rapeseed intercropped with frost-sensitive legumes decided by one cooperative (Tab. 6), but this increase of more than 3 times resulted in less than $2 \%$ of the total area of rapeseed intercropped with frost-sensitive legumes.

In addition, 3 cooperatives had objectives that could not be verified with the information collected in the survey (data not presented): to diagnose how DSSs were being used ( 2 cooperatives) or to increase the use of Global Positioning Systems to apply nitrogen fertilizers (1 cooperative).

\section{Discussion and conclusion}

The results suggest that the production of very low GHGemitting rapeseed biodiesel is possible in France in certain locations and/or years if improved cultivation operations are adopted. However, the changes in cultivation operations observed were too small to be effective and sometimes the result was a decrease in the adoption of good practices. This lack of results can be explained firstly by the lack of obligation of results in the contracts signed between the cooperatives/ companies and SAIPOL. Indeed, SAIPOL's objective was to stimulate innovations in cultivation operations to reduce GHG emissions in rapeseed, both by communicating on this issue to motivate the cooperatives/companies and by offering the possibility to have a monitoring of GHG emissions and suggestions for improvement. The lack of results could then be explained by the lack of motivation of cooperatives/companies. SAIPOL believed that cooperatives/companies would see their own interest in reducing GHGs, as this would be a way to ensure the $50 \%$ reduction of GHGs and thus the sustainability of rapeseed. In 2013, it was requested to take into account the indirect land use change due to biofuel production, or to increase the GHG reduction target to $60 \%$, which would have meant the need to reduce GHG emissions from rapeseed as most NUTS2 values would have been too high to produce a sustainable biodiesel. However, this prospect seems to have been too far away to motivate cooperatives/companies. For farmers it was even worse. They were not sufficiently aware of the end use of their crop production, their knowledge of the impacts of cultivation operations on GHG emissions was low and most of them did not even know that GHGs were calculated for their own rapeseed fields. Therefore, the first lesson of this study is the need to share problems among all participants in order to achieve good results. This is in line with the study of Montrone (2015) which showed that one of the main conditions for successfully improving cultivation operations was stakeholder coordination. Therefore, in the future, biodiesel industries should increase their efforts to establish a collaborative and constructive dialogue with farmers and cooperatives/companies, involving frequent feedback, plant visits, distribution of goodies,..., in order to 
make the objective less abstract, to show them the role they can play and to create a sense of belonging. This will have to be done with a low administrative burden, which has been too high so far. The data have been collected in different ways, including the use of the database but also by hand-filled forms. In addition, the calculations and reporting of results have been time-consuming, too often involving human operators. Another explanation for the failure to improve cultivation operations was the feeling that there was nothing that could be done, as GHG emissions were strongly influenced by natural conditions (climate and soil), through their effects on seed yields. Moreover, the most effective way to improve cultivation operations is at the level of the cropping system: it is difficult to motivate changes involving the cultivation of new legume crops for an issue that only concerns rapeseed. It was therefore decided to replace the "Démarche de progrès DIESTER ${ }^{\mathbb{B}}$ " initiative by a cropping system improvement strategy aimed at solving the agronomic problems encountered by farmers (soil fertility, insect and weed resistance to pesticides, etc.), improving profitability and reducing environmental impacts. These improved cropping systems will produce the low environmental impact seeds needed for certain food and non-food industries. This project, led by the AVRIL Group, was launched in 2020 to produce low environmental impact edible oil, animal feed cake and biodiesel from improved cropping systems and industrial processes.

Acknowledgements. The authors wish to thank SAIPOL and AVRIL group for the financial support and for the coordination of this study.

\section{References}

BIO IS. 2010. Analyses de Cycle de Vie appliquées aux biocarburants de première génération consommés en France-Rapport final. Paris (France) : Publications de l'ADEME.

Ben Aoun W. 2015. Le développement de la filière biodiesel de colza en France: Evaluation des impacts environnementaux et des conséquences sur l'usage des sols. Thèse de Doctorat ParisTech.

Cadoux S, Sauzet G, Valantin-Morison M, et al. 2015. Intercropping frost-sensitive legume crops with winter oilseed rape reduces weed competition, insect damage, and improves nitrogen use efficiency. OCL 22(3): D302.

Christen O, Sieling K. 1995. Effect of different preceding crops and crop rotations on yield of winter oil-seed rape (Brassica napus L.). J Agron Crop Sci 174: 265-271.

De Klein C, Novoa RSA, Ogle $\mathrm{S}$, et al. $\mathrm{N}_{2} \mathrm{O}$ emissions from managed soils, and $\mathrm{CO}_{2}$ emissions from lime and urea application. In: 2006 IPCC Guidelines for National Greenhouse Gas Inventories, 2006.

Dumans P, Flénet F, Wagner D, Bonnin E, Schneider A. 2010. Prise en compte des effets précédents dans la rentabilité des cultures. Pour gagner plus avec du colza, placez-le après un pois! Perspectives Agricoles 368: 4-8.

Flénet F. 2012. Mitigation of greenhouse gas emissions in the French winter oilseed rape in order to produce sustainable biodiesel. $O C L$ 19: 164-168.

Gabrielle B, Laville P, Duval O, Nicoullaud B, Germon JC, Hénault C. 2006. Process-based modeling of nitrous oxide emissions from wheat-cropped soils at the subregional scale. Global Biogeochem Cycl 20: GB4018. https://doi.org/10.1029/2006GB002686.

Gac A, Deltour L, Cariolle M, et al. 2009. GES'TIM-Guide méthodologique pour l'estimation des impacts des activités agricoles sur l'effet de serre. Paris (France): Publications de l'institut de l'élevage.

Gaillard G, Hausheer J, Crettaz P. 1997. Inventaire environnemental des intrants agricoles en production végétale, base de données pour l'établissement de bilans énergétiques et écologiques en agriculture. Suisse: Publications de la station fédérale de recherches en économie et technologie agricole.

Godron E. 1992. Coûts d'utilisation de machines agricoles. Travaux et innovation 92(07): 19-23.

Green MB. Energy in pesticide manufacture, distribution and use. In: Helsel ZR, ed. Energy in plant nutrition and pest control. Amsterdam (Nederland): Elsevier, 1987.

ITCF. 1995. BASEMEQ: base de données mécanisation de l'ITCF. Paris (France) : Publications de l'ITCF.

Makowski D, Maltas A, Morison M, Reau R. 2005. Calculating N fertilizer doses for oilseed rape using plant and soil data. Agron Sustain Develop 25: 159-161.

Montrone E. 2015. Étude des démarches des organismes stockeurs visant une agriculture durable. Mémoire de fin d'études pour l'obtention du diplôme d'ingénieur Agrocampus Rennes.

Cite this article as: Flénet F, Wagner D, Simonin P. 2020. Examination of an attempt to improve rapeseed cultivation in France in order to reduce the greenhouse gas emissions of biodiesel. OCL 27: 69 . 